\title{
From the Desk of the Editor
}

\author{
K. S. Gopinath
}

Received: 3 May 2012 / Accepted: 3 May 2012 / Published online: 17 May 2012

(C) Indian Association of Surgical Oncology 2012

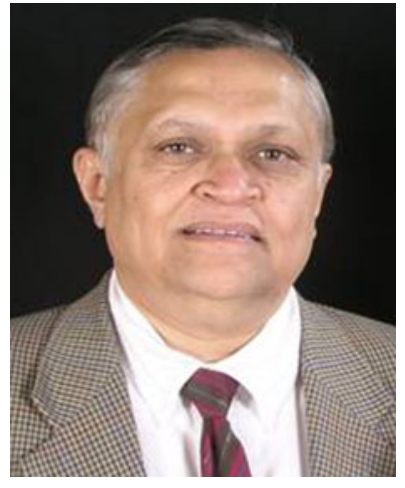

The Indian Journal of Surgical Oncology has made a progress and entering in to the third year, with a good response by all oncologists in this country and across the globe.

The number of submissions received in few weeks really indicates that Indian Association of Surgical Oncologist a section of association of surgeons of India has created an awareness among its members to be more academic and also it induced enthusiasm to publish. The various statutory bodies in the country involved in medical education has taken a leap forward that professionals in the training programme both for faculty as well as for the trainees made it mandatory to publish their work for their progress in their institution, could be one of the factors for increased number of submissions to the journal.
As usual Springer Inc team is very actively involved and carrying the work to the satisfaction of all concerned.

This is an important year for us in IJSO to make progress and get better accreditation from renowned agencies; we hope this year we will succeed in achieving it. Many substantiate, initiatives are being implemented that represent a continued commitment to provide timely service to our readership, authors and patients whom we treat.

There is a changing trend in multimodality treatment, looking out for economic impact on the treatment offered to patient's in our country. We have to consider both evidence base and economy based treatment, with all the advances made. The dilemma remains regarding utilization of technology an evidenced based especially in minimal invasive surgery and robotic surgery.

This year we have an issue dedicated to Uro-Oncology, where in several authors of eminence both nationally and across the Globe as contributed to the journal, helping all the readers to update their knowledge as well as skill. The subsequent issue of the journal will be devoted to the publication from the individuals and hope by the end of the year we will have accreditation from all the concerned.

I look forward to the exciting adventure that will succeed only through the hard work of many individuals including our dedicated associate editors and editorial board, the wonderful administrative staff and our readers all of whom contribute to make this journal very useful.

\footnotetext{
K. S. Gopinath $(\bowtie)$

Bangalore Institute of Oncology, Ambuja Health Care,

Bangalore 560027, India

e-mail: gopiijso@gmail.com
} 